http://dx.doi.org/10.18675/1981-8106.vol25.n49.p312-325

\title{
Reflexões Sobre a Educação do Campo na Perspectiva Pedagógica da Indignação
}

Thoughts on Rural Education in Pedagogical Perspective of Indignation

\section{Reflexiones Sobre la Educación del Campo en la Perspectiva Pedagógica de la Indignación}

\author{
Vilson Alves Moreira' \\ Fábio Lima Beck" \\ 'Instituto Federal do Norte de Minas Gerais (IFNMG), Câmpus Salinas, Minas Gerais - Brasil. E-mail: \\ vilsonam1@yahoo.com.br \\ "Universidade Federal do Rio Grande do Sul (UFRGS), Porto Alegre, Rio Grande do Sul - Brasil. E- \\ mail: samelo@ufrgs.br
}

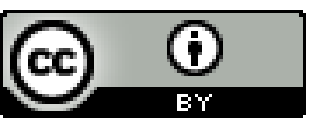

Educação: teoria e prática, Rio Claro, SP, Brasil - eISSN: 1981-8106

Está licenciada sob Licença Creative Common

\section{Resumo}

O direito à educação tem sido considerado passaporte dos cidadãos à autonomia e à dignidade humana, bem como condição sinequa non da possibilidade de desenvolvimento e crescimento com equidade social e econômica de uma nação. A uma categoria específica desses cidadãos, no entanto, tem sido negado tal direito a uma educação de qualidade, condizente com sua realidade socioeconômica e cultural. É o que tem sido manifestado pelas reivindicações dos movimentos populares dos meios urbano e rural. As classes populares e, em especial os camponeses, anunciam sua indignação, exigindo um olhar particular dos poderes públicos para sua carência educacional ou agindo propositivamente com projetos alternativos, de modo a buscar um ensino adequado a seus objetivos. Neste contexto, políticas públicas que atendam a tais reivindicações são vistas como necessárias, além de enfocarem a formação e a prática transformadora dos agentes mediadores da educação, os docentes. Necessária, também, será a construção de currículos e de infraestrutura básica, dando condição de oferta de um ensino adequado à realidade desses grupos de indivíduos que ainda não foram atendidos na plenitude da sua cidadania. 
Palavras-chave: Educação; Sociedade; Prática pedagógica.

\begin{abstract}
The right to education has been considered passport to citizens autonomy and human dignity, as well as sine qua non condition to the possibility of development and economic growth and social equity as a nation. A specific category of these citizens, however, has been denied this right to a quality education consistent with their socioeconomic and cultural reality. Such right has been expressed by the claims of popular movements of urban and rural areas. The classes and especially the peasants announce their indignation, demanding a particular look by the public authorities to their lack of education or acting with proposals as alternative projects in order to get a proper education to their goals. Then, the need for public policies to meet such claims are vital, but they should pay attention to the training and teaching practice of transformative mediator agents of education, the teachers. Building resumes and basic infrastructure will also be required to give conditions for offering appropriate education according to the reality of these people who have not yet been full-fledged citizens in society.
\end{abstract}

Keywords: Education; Society; Teaching practice.

\title{
Resumen
}

El derecho a la educación ha sido considerado pasaporte de los ciudadanos para la autonomía y la dignidad humana, así como condición sine qua non de la posibilidad de desarrollo y crecimiento con equidad social y económica de una nación. Sin embargo, a una categoría específica de estos ciudadanos se les ha negado tal derecho a una educación de calidad, correspondiente con su realidad socioeconómica y cultural. Es lo que ha sido manifestado por las reivindicaciones de los movimientos populares de los medios urbano y rural. Las clases populares y, en especial los campesinos, anuncian su indignación, exigiendo una mirada particular de los poderes públicos para su carencia educacional o una actuación propositiva con proyectos alternativos, a modo de buscar una enseñanza adecuada a sus objetivos. Por tanto, unas políticas públicas que atiendan a tales reivindicaciones son vistas como necesarias, además de enfocar la formación y la práctica transformadora de los agentes mediadores de la educación, los docentes. Necesaria, también será la construcción de currículos y de infraestructura básica, dando condición de oferta de una enseñanza adecuada a la realidad de estos grupos de individuos que aún no fueron atendidos en la plenitud de su ciudadanía.

Palabras clave: Educación; Sociedad; Práctica pedagógica. 


\section{Introdução}

Constata-se que têm surgido contundentes debates em torno da luta dos movimentos sociais, urbanos e rurais, por uma educação adequada ao seu contexto, a partir de uma pedagogia da indignação. Esses movimentos pensam e repensam práticas educativas na relação social, elaboram propostas pedagógicas transformadoras e, ainda, protagonizam experiências pedagógicas inovadoras.

Desafiado por essas proposições, este trabalho vem discutir questões que permitam compreender a importância de educação e práticas pedagógicas específicas para a formação das classes populares. Assim, sob a luz de teóricos da educação popular como Paulo Freire e Miguel Arroyo, dentre outros, se realiza a presente reflexão. Observa-se que se faz necessário um olhar especial aos agentes mediadores - os docentes - na construção do conhecimento junto a determinadas realidades sociais carentes de mudanças.

A reflexão, aqui proposta, é orientada para a necessidade de uma pedagogia própria para a indignação, pois essa pedagogia permite interagir, de maneira crítica e propositiva, com as características socioeconômicas e culturais do nosso país. Assim, apresentam-se apontamentos que implicam na constituição de novos paradigmas pedagógicos para as políticas educacionais públicas urbanas e rurais.

Uma das questões centrais com que temos de lidar é a promoção de posturas rebeldes em posturas revolucionárias que nos engajam no processo radical de transformação do mundo. A rebeldia é o ponto de partida indispensável, é deflagração da justa ira, mas não é suficiente. A rebeldia enquanto denúncia precisa se alongar até uma posição mais radical e crítica, a revolucionária, fundamentalmente anunciadora. A mudança do mundo implica a dialetização entre a denúncia da situação desumanizante e o anúncio de sua superação; no fundo, o nosso sonho (FREIRE, 2000, p.81).

\section{A educação na Dinâmica do Processo Social}

Para Arroyo (2009), há um movimento no processo educacional popular urbano e rural representado nas lutas reivindicatórias e nos projetos propositivos dos movimentos sociais dos camponeses e dos proletários. Esse movimento se verifica, também, nas respostas dos agentes públicos às pressões dos movimentos sociais. Comprova-se, assim, que há uma nova dinâmica no tratamento à questão da educação popular urbana e rural, que é reflexo das características socioeconômicas, culturais e tecnológicas do mundo atual.

Como estudioso do campo educacional, Arroyo(2004a, 2004b, 2009, 2010)acusa que os movimentos sociais populares têm desenvolvido, de maneira relevante, uma luta crítica e propositiva por uma educação de qualidade. Tais lutas têm forçado órgãos públicos a atenderem às suas demandas e, em especial, aquelas relacionadas à educação do campo. 
Também, os estudos sobre educação popular, que se inspiram nos fundamentos teóricos freirianos, guiam para uma necessária adequação da compreensão do processo pedagógico aplicado aos filhos dos trabalhadores urbanos e rurais. Vale lembrar que a construção do pensamento educacional de Paulo Freire se deu com os sujeitos excluídos, oprimidos e marginalizados pelas políticas públicas do capitalismo produtivista e de mercado. Sujeitos que se enquadram entre as camadas sociais que estão à margem de uma educação de qualidade defendida por Freire (1996): democrática, dialógica, contextualizada e transformadora.

Apesar da carência de pesquisadores e de produção teórica na temática educacional e, principalmente, na área da educação do campo, além dos autores já citados, encontramos Roseli Caldart, Bernardo Mançano Fernandes, Mônica Castanha Molina, Marlene Ribeiro, dentre outros. Esses autores procuram novos conceitos para a compreensão da importância da educação do campo. Apontam para aquela educação que está gestada pelos movimentos sociais. "... o conceito de educação do campo tem raiz na sua materialidade e origem no movimento histórico da realidade a que se refere" (CALDART, 2008, p.69). Duarte(2006, p.69) contribui para essa reflexão, caracterizando três correntes de pesquisas presentes na educação atual: as que estão "voltadas para a construção de um discurso pedagógico afirmativo sobre a transmissão de conhecimentos na escola"; as que estão "voltadas para a elaboração de análises críticas das pedagogias subsumidas ao universo ideológico neoliberal e pós-moderno" e "aquelas voltadas para o desenvolvimento de análises críticas da realidade educacional na sociedade contemporânea". Sendo que a última é mais expressiva e se movimenta inspirada nos movimentos sociais pela educação pública e do campo.

Como aponta Bauman (2002), devemos compreender que vivemos, na contemporaneidade, a transição de uma sociedade sólida de certezas para um novo contexto de modernidade, líquida de incertezas, onde permanecem as classes sociais em suas estratificações. Dessa maneira, o domínio do conhecimento reflexivo se faz ainda mais necessário aos indivíduos para sua sobrevivência nessa sociedade. Nesse contexto, a educação tem papel estratégico, capacitando indivíduos para atuação nessa nova realidade social em que múltiplos interesses estão em jogo.

Conforme Bauman (2002) a oferta da educação para determinadas classes,em nossa sociedade, tem uma característica discriminadora que reforça a estratificação social, estabelecendo a função de cada uma no processo produtivo e participação política, ou seja, a educação ofertada aos cidadãos das classes desfavorecidas é um produto fixo, imóvel, não dinâmico. Dessa maneira, os indivíduos das citadas classes são formados com habilidades e competências voltadas à reprodução de comportamentos automatizados, tornando-os não críticos e não criativos. Opõe-se a isso organizações e movimentos sociais, dentre outros que compreendem a educação enquanto processo dinâmico e inalienável.

A contemporaneidade, então, desafia para um agir atento a uma formação que prepare os cidadãos para atuar, nesse tempo de transições e conflitos, valendo-se de uma educação conforme as características específicas do tempo hodierno, carregado de múltiplos interesses. 
Diante dos planos políticos neoliberais para a educação, segundo Gadotti (1997), Freire nos apresenta uma pedagogia da esperança que nos leva a acreditar na possibilidade da mudança via educação, contrariando a imobilidade do tecnicismo educacional contemporâneo. Acrescente-se que a pedagogia freiriana humaniza a educação, pois a mesma é para servir o ser humano. Não podendo ser utilitarista e tecnicista, a educação deve fazer os homens mais humanos.

\begin{abstract}
A pedagogia do oprimido, como pedagogia humanista e libertadora, terá, dois momentos distintos. O primeiro, em que os oprimidos vão desvelando o mundo da opressão e vão comprometendo-se na práxis, com a sua transformação; o segundo, em que, transformada a realidade opressora, esta pedagogia deixa de ser do oprimido e passa a ser a pedagogia dos homens em processo de permanente libertação (FREIRE, 1987, p.23).
\end{abstract}

Em Arroyo (2009) é encontrada, também, a indignação, quando argumenta em sua teoria reflexiva enraizada na realidade socioeducacional dos trabalhadores, em particular os rurais: argumenta que as exigências dos novos tempos não permitem que o Estado continue a ignorar a educação do campo, a qual cobra uma atenção diferente daquela que recebeu no passado, ou seja, cobra o reconhecimento de identidade ética, cultural e de valores próprios. Uma formação que atenda e respeite à diversidade dos povos do campo no contexto contemporâneo.

A educação, enquanto transmissão e construção do conhecimento, pela sua importância na formação dos indivíduos, passa pela intenção da conservação ou transformação da realidade que os cerca. Nela, é estabelecido um campo de batalha para controle e imposição dos interesses de grupos diversos. Em que pesem as propostas e ações do Estado para a educação do campo, Arroyo(2004a), alerta para questões pontuais que não podem ser ignoradas. Tais questões são importantes no equacionamento das problemáticas na educação rural: ao ignorar o direito à educação rural dos camponeses, o Estado os coloca numa condição de cidadãos de segunda categoria. Daí, tem-se, também, a necessidade de medidas urgentes para se recuperar ou minimizar tal prejuízo, através de políticas compensatórias que fomentem estudos, analisando e desvelando a situação precária do sistema educacional do campo.

Essas políticas reorientariam para uma maior eficiência das ações do Estado em suas políticas públicas de investimentos na reelaboração de currículos, formação docente, materiais didáticos etc. Nesse contexto, por exemplo, pode-se apontar o que acontece com as classes multisseriadas que estão, predominantemente, no campo e necessitando de novos olhares das políticas públicas.

[...]as classes multisseriadas merecem outros olhares. Predominam imaginários extremamente negativos a ser desconstruídos: a escola 
multisseriada pensada na pré-história de nosso sistema escolar; vista como distante do paradigma curricular moderno, urbano, seriado; vista como distante do padrão de qualidade pelos resultados nas avaliações, pela baixa qualificação dos professores, pela falta de condições materiais e didáticas, pela complexidade do exercício da docência em classes multisseriadas, pelo atraso da formação escolar do sujeito do campo em comparação com aquele da cidade[...] (ARROYO, 2010, p.10).

Identifica-se em Arroyo a defesa não só de políticas compensatórias de investimentos na infraestrutura da educação, mas, também, na proposição de práticas pedagógicas que expressem uma pedagogia adequada ao contexto social e ao universo material e imaterial dessas populações, como no caso dos camponeses, em que devem ser reconhecidas também suas potencialidades de produção socioeconômica e cultural.

Mas, pode-se observar que, infelizmente, ainda se faz presente nas escolas rurais, em pleno século XXI, o patrimonialismo, onde ocorre o agenciamento político e privado das instituições escolares, objetivando o controle das lideranças educacionais.

Segundo Arroyo (2004a), a educação no meio rural tem sofrido uma mercantilização, com práticas manipuladoras para atender interesses outros, e menos para resolver os problemas do ensino rural. Um exemplo é o que ocorre com as nucleações das escolas rurais. Essa prática desloca os alunos de seu contexto cultural, ignorando os sistemas produtivos alternativos dos camponeses. Igualmente, as qualificações profissionalizantes tecnológicas ofertadas a esses indivíduos do campo, em grande parte, não atendem aos seus interesses, mas aos da agricultura patronal.

Assim como o sistema industrial mudou a dinâmica do urbano, também o campo hoje é outro, ou seja, exige políticas públicas diferentes daquelas do passado ou que até mesmo nem existiam. Isso é demonstrado nas ações dos movimentos sociais que avançaram e se tornaram mais eficientes em sua militância por direitos. Não só reivindicam, mas propõem projetos sob uma gestão autônoma dos trabalhadores urbanos e rurais. De acordo com Fernandes (2004), há um novo paradigma na educação do campo, o qual defende formações contextualizadas a cada classe social do meio rural, ou seja, formações que busquem atender às demandas da agricultura familiar e também ao mercado de trabalho do agronegócio. A primeira, graças especificamente à ação do movimento reivindicatório popular.

\section{Educação, Controle e Saber}

O surgimento da propriedade privada contribuiu para a estratificação socioeconômica, consequentemente se fez necessário um instrumento de controle e formação ideológica das classes que se opõem. Embora se defenda que a educação deva estar para o atendimento da formação do cidadão integral para uma atuação de visão holística na sociedade, o que se aplica, em efetivo, nessa sociedade, é uma educação que se torna um sistema de formação 
para atendimento das necessidades e funções específicas dos indivíduos enquanto classes sociais. Daí, que Freire alerta sobre a importância da formação do educador.

Os nossos futuros mestres [...] deveriam estar sendo formados com alto senso de responsabilidade profissional [...] cônscios de seu papel altamente formador. Esta convicção, porém, como aquela consciência, dificilmente se forma em quem assume postura passiva. Em quem não é inserido num processo dialogal (FREIRE, 2002, p. 101-102).

Embora permita o controle social, a educação caracteriza-se, também, como arena de embates entre diversos atores com os seus mais variados interesses, sejam individuais ou coletivos. Busca-se o controle não apenas do conteúdo que deve ser ensinado, dos instrumentos e aparelhos institucionais, mas de uma pedagogia própria para transformação ou conservação da realidade.

Numa corrente mais crítica e interacionista, encontra-se, novamente em Paulo Freire, a concepção de uma pedagogia onde a formação e a prática pedagógica reflexiva exercem um papel ativo, interpretativo e dialético sobre o saber, contextualizando-o ao cotidiano do universo social, ao ensino e ao aluno. Como consta na seção Ensinar exige reflexão crítica sobre a prática, de sua obra Pedagogia da Autonomia:

[...] se precisa é possibilitar, que, voltando-se sobre si mesma, através da reflexão sobre a prática, a curiosidade ingênua, percebendo-se como tal, se vá tornando crítica. Por isso é que, na formação permanente dos professores, o momento fundamental é o da reflexão crítica sobre a prática. É pensando criticamente a prática de hoje ou de ontem que se pode melhorar a próxima prática. O próprio discurso teórico, necessário à reflexão crítica, tem de ser de tal modo concreto que quase se confunda com a prática (FREIRE, 1996, p. 42-44).

A prática pedagógica se reflete no conhecimento transmitido pelos instrumentos escolhidos ao fazer uso dos elementos didáticos, pedagógicos e saberes que a constituem. Assim, o educador domina e aplica o saber no seu cotidiano profissional, junto aos discentes e sobre os quais reflete criticamente. Consequentemente, pela dinâmica da relação família e escola, essa reflexão se estende também aos universos sociais deles.

O saber constituído no sistema educacional é um significativo instrumento que dá poder e habilita os atores sociais na produção dos bens materiais e imateriais. Ele os empodera para manter e ampliar espaços, para impor seus projetos na sociedade em que vivem e atuam. Conforme Freire, o saber e o conhecimento transmitidos ou construídos na ação do educador estão à mercê de uma ocultação, ou não, a depender de sua atuação como formador. 
Se a reprodução da ideologia dominante implica, fundamentalmente, a ocultação de verdades, a distorção da razão de ser de fatos que, explicados, revelados ou desvelados trabalhariam contra os interesses dominantes, a tarefa das educadoras e dos educadores progressistas é desocultar verdades, jamais mentir. A desocultação não é de fato tarefa para os educadores a serviço do sistema (FREIRE, 2001, p. 98).

Fundamentando nas análises propositivas e críticas de Arroyo (2004b, 2009) a reivindicação da universalização da educação básica no campo, como projeto pontua que não basta promulgar leis ou ter simples reconhecimento por ministérios, conselhos ou secretarias governamentais sobre a vulnerabilidade dessa educação. É preciso investir de forma concreta e objetiva. Por exemplo: priorizando a educação do campo nas agendas políticas, garantindo infraestrutura física para as escolas do campo, responsabilizando politicamente as instâncias federativas com a intervenção específica de cada uma, normatizando determinações obrigatórias de investimentos (como qualificação profissional, estabilidade profissional, plano de carreira docente, salários dignos para servidores da educação rural, dentre outros aspectos). Esses elementos sinalizariam para um projeto de redirecionamento das políticas públicas para o ensino e, em particular, para o ensino no campo.

Como referido anteriormente, atores sociais, de forma individual ou coletiva, criam uma arena de disputa ao impor projetos de formação educacional condizentes com a sua classe. Isso é evidenciado no confronto entre a educação ofertada às elites, que qualifica os seus membros para o gerenciamento político da sociedade, em contraposição à educação dada aos cidadãos das camadas populares, que visa apenas a qualificá-los com um saber fazer mecânico no processo produtivo econômico.

Assim, as estratégias de ação com predominância de recursos econômicos se apossam de um capital político, buscando controlar as regras dos projetos educacionais do Estado. De outro lado, os possuidores da força do trabalho estrategicamente apontam modelos alternativos de educação e propostas pedagógicas, tais como as Escolas Famílias Agrícolas, Casas Familiares Rurais, Escolas do Movimento dos Sem-Terra etc. Além disso, articulam-se na busca de capital político, levando o Estado a atendê-los com políticas públicas de educação voltadas aos seus interesses. Isso já ocorre no Brasil com a educação do campo através das ações do Programa Nacional de Educação na Reforma Agrária (PRONERA) e do (ex)Programa Escola Ativa (PEA) coordenados, respectivamente, pelo Instituto Nacional de Colonização e Reforma Agrária (INCRA) e Secretaria de Educação Continuada, Alfabetização, Diversidade e Inclusão (SECADI), órgãos do governo federal brasileiro.

Destaque-se, ainda, a implantação do PRONACAMPO (Programa Nacional de Educação do Campo) que teve seu lançamento em março de 2012 em substituição ao PEA. Os eixos de ação desse programa abrangem a gestão e práticas pedagógicas, formação de professores, educação profissional e tecnológica e infraestrutura, tendo como sujeitos as escolas do campo e comunidades quilombolas. Como vários programas oficiais de governo, 
elaborados como respostas às pressões dos movimentos sociais, o programa sofre críticas desses mesmos movimentos, sob a alegação de que não atende ao modelo educacional reivindicado.

$\mathrm{Na}$ busca de uma educação para o homem do campo, Caldart(2009) define sua caracterização respaldada na luta dos movimentos sociais do campo.

[...] a identidade [..] por uma educação do campo é a luta do povo do campo por políticas públicas que garantam o seu direito à educação e a uma educação que seja no e do campo. No: o povo tem direito a ser educado no lugar onde vive; Do: o povo tem direito a uma educação pensada desde o seu lugar e com a sua participação, vinculada à sua cultura e às suas necessidades humanas e sociais (CALDART, 2009, p. 149, 150).

O ponto central dessa educação específica para as camadas populares rurais (mas também urbanas) está na formação e na prática pedagógica do docente - o mediador -ao transmitir conteúdos e concepções éticas, morais e políticas. A seção seguinte busca refletir sobre a intervenção desse agente.

\section{A Pedagogia na Atuação Docente}

É reconhecida a importância da educação como um instrumental estratégico para qualquer desenvolvimento. E, para que isso ocorra, deve-se possibilitar a formação de cidadãos autônomos livres e defensores de um mundo produtivo participativo em seus resultados da transformação da natureza pelo trabalho e político com justiça e democracia, onde subsista uma equidade social. Nesse universo não se pode ignorar a presença e o papel do professor como um agente ímpar de mediação no processo de formação dos indivíduos.

Segundo Freire (1996), o papel do professor é fundamental no processo educacional quando do mesmo se exige uma prática educativa que desperte o discente para a criticidade, gerando conhecimento que o liberte. Afirma, também, que:

O povo [...] enquanto esmagado e oprimido, introjetando o opressor, não pode sozinho, constituir a teoria de sua ação libertadora. Somente no encontro dele com a liderança revolucionária, na comunhão de ambos, na práxis de ambos, é que esta teoria se faz e se re-faz (FREIRE, 1987, p.107).

Tem, ainda, o professor, a missão de problematizar a realidade vivida pelos seus alunos para que assim não só recebam, mas também produzam o saber contextualizado ao cotidiano. A mediação para o conhecimento também é dada pelo mundo, cabendo ao 
professor, na sua competência e habilidade pedagógica, reconhecer todo aprendiz como sendo um sujeito já competente e carregado da cultura do seu contexto social (FREIRE,1996).

Giroux (1997) chama atenção para a atuação dos docentes e instituições no processo multidimensional da formação tecnológica, política, ética, moral e cidadã dos indivíduos. $\mathrm{O}$ papel de mediador do educador, na sociedade contemporânea, exige dele uma formação que sensibiliza a indignação com ação transformadora, compreendendo, para isso, a visão crítica e a necessidade de práticas democráticas. Essa atuação acaba se refletindo no acesso e permanência do discente na escola, pois ocorre valorização de saberes contextualizados à realidade local, possibilitando, assim, o seu desenvolvimento.

Freire (1996) destaca, em sua concepção pedagógica da autonomia, que o processo de ensino e aprendizagem pressupõe respeito e participação de todos os sujeitos envolvidos na construção do conhecimento, em que cada um contribui com o que sabe e aprende o que é ensinado. Desta maneira, todo educador enquanto pessoa física ou jurídica, têm compromisso em oferecer aos cidadãos uma formação que potencialize seus valores humanos éticos e morais para além do mero conhecimento intelectual e técnico.

A proposta pedagógica de Freire (1996) recupera o valor e a importância da educação para toda a sociedade, não podendo o acesso à mesma ser privilégio de grupos sociais majoritários economicamente, como ocorre na sociedade capitalista.

O homem do campo, assim como os trabalhadores urbanos, vive numa relação objetiva e prática com a realidade, daí que uma prática pedagógica meramente memorizadora ou tecnicista não condiz com sua condição. Freire (1996) apud GADOTTI, 1989, p.69, propõe a educação problematizadora que "funda-se [...] justamente na relação dialógico-dialética entre educador e educando: ambos aprendem juntos". Essa educação deve suplantar a educação bancária que é: "a educação torna-se um ato de depositar (como nos bancos); o "saber" é uma doação, dos que se julgam sábios, aos que nada sabem".

Essa perspectiva também aparece em Souza:

A defesa da Educação do Campo vem valorizar o camponês, o trabalhador assalariado rural, e especialmente, o direito social à educação pública. [...] a necessidade de formação de professores voltados à Educação do Campo de modo a melhorar a realidade pedagógica das escolas do campo (SOUZA, 2010, p. 236).

Para Freire (1987), é preciso confrontar a relação teoria e prática, compreendendo teoria como o resultado de um exercício de reflexão crítica sobre uma determinada realidade. O indivíduo se reconhece agindo na mudança das coisas, numa ação dialética e a práxis é a "ação e reflexão dos homens sobre o mundo para transformá-lo" (FREIRE, 1987. p. 38). 
$\mathrm{Na}$ defesa de uma educação para os povos do campo, é perceptível que as políticas públicas nas nações pouco desenvolvidas ou em desenvolvimento, como no Brasil, pouco têm dado atenção ao valor dos docentes enquanto mediadores. Ignoram a importância e a responsabilidade destes na administração dos interesses de todas as camadas sociais de forma justa e democrática. Também em Giroux (1997), é percebida a prática de impossibilitar aos educadores o exercício pleno e eficiente do seu papel de mediador, de construtor e multiplicador do saber nas camadas populares.

Conforme Freire,

Do ponto de vista, porém, dos interesses dominantes, é fundamental defender uma prática educativa neutra, que se contente com o puro ensino, se é que isto existe, ou com a pura transmissão asséptica de conteúdos, como se fosse possível, por exemplo, falar da "inchação" dos centros urbanos brasileiros sem discutir a reforma agrária e a oposição a ela feita pelas forças retrógradas do país (FREIRE, 2001 p.102).

Por sua natureza política, o educador, enquanto mediador e agente de desenvolvimento, tem que escolher entre duas opções: ou mantém os objetivos estabelecidos pelos programas educacionais convencionais, dos quais, muitas vezes, ele é o representante, ou se posiciona pela construção de saberes que levam à mudança da ordem social. Como bem aponta Nóvoa (1991), embora não seja a escola a única responsável pelo desenvolvimento, é dela que mais se cobra essa possibilidade.

Damasceno (1990, p.29) entende a educação como um instrumento de relação histórica dialética que possibilita o domínio, o poder das pessoas ou classes. Por isso especifica que a educação é um "Projeto político que se vincula à dialética de classes", sua atuação está na "reelaboração do saber, da cultura, e da visão de mundo do grupo onde a educação se insere e as relações de poder que se estabelecem e se formam mediante a ação pedagógica".

Dessa maneira, se confirma o papel do educador em contribuir com a transformação social pelo instrumental educacional, desmitificando a possível neutralidade de agente construtor e mediador do saber.

Diante do processo acelerado e dinâmico pelo qual passa a sociedade, exige-se uma compreensão interacionista e sistêmica de sua organização socioeconômica globalizada. Nesse contexto, a formação e a prática do docente na educação, em especial do campo, demandam uma pedagogia reflexiva e crítica motivada por uma atitude de indignação que conduza a uma ação transformadora dos cidadãos, promovendo o crescimento $\mathrm{e}$ desenvolvimento social, econômico e cultural. 


\section{Considerações Finais}

Os debates teóricos e de militância ativa a favor da educação popular e do campo defendem políticas públicas focadas em uma pedagogia específica, guiada pela indignação. Essa pedagogia orienta a formação e a prática do docente de forma dinamizadora e contextualizada à realidade social da classe trabalhadora, em especial a rural, carente de uma formação mais específica ao seu contexto e modos de vida.

Ao refletir sobre a necessidade dessa pedagogia, se reconhece a carência de sustentações teóricas para a constituição de conceitos e teses que permitam conclusões críticas aplicáveis à realidade da educação. Reconhece-se, também, serem escassos não só os investimentos das políticas públicas de educação, mas as contribuições científicas para construção de referenciais teóricos que possibilitem o incentivo ao desenvolvimento social, em especial das camadas populares urbanas e rurais.

Compreende-se, assim, a urgência da democratização ao acesso e à permanência dos menos favorecidos a um sistema educacional de qualidade. Nesse contexto, cobra-se atenção especial às camadas sociais mais vulneráveis e privadas da dignidade humana, que precisam ter direito a uma formação educacional que lhes permita inserirem-se como cidadãos na sociedade contemporânea, e responder adequadamente aos desafios do mercado de trabalho.

Como já exposto, a educação no contexto contemporâneo revela-se carente de uma pedagogia da indignação como instrumento que transforme o sistema educacional. No entanto, já se observa que, pela indignação de sujeitos pensantes e ativos, estão surgindo frutíferos modelos antagônicos às propostas educacionais conservadoras.

O resgate da memória histórica dessas lutas e conquistas torna-se importante para o fortalecimento da consciência e do poder das camadas populares. Fica claro que estão sendo construídos modelos sociais, econômicos, políticos e culturais alternativos, e que já se fazem presentes em nosso meio em propostas educacionais diversas, como a pedagogia da alternância, dentre outras.

Como afirma o patrono da educação brasileira, Paulo Freire, só é possível a transformação da sociedade a partir da via educacional. Então, para isso, faz-se necessário que cidadãos e militantes conscientes, em todas as instâncias da sociedade, atuem de maneira indignada e propositiva.

\section{Referências}

ARROYO, M. G. Por um tratamento público da Educação do Campo. In: MOLINA, M.C.; DE JESUS, S.M.S.A. (Orgs.). Por uma Educação do Campo: contribuições para a construção de um projeto de Educação do Campo. Articulação Nacional por uma Educação do Campo: Brasília: MEC , 2004a. P. 54 - 62. 
ARROYO, M. G. Política pública de educação no campo. In: BRASIL. Câmara dos Deputados. Uma Política Pública para a Educação do Campo: Seminário. Brasília: Coordenação de Publicações da Câmara dos Deputados, 2004b. p. 66-86. (Série ação parlamentar, n. 277).

ARROYO, M. G. A educação básica e o movimento social do campo. In:

CALDART, R.S.; MOLINA, M.C. (Orgs.). Por uma educação do campo. 4 ed. Petrópolis: Vozes, 2009. p. 65-86.

ARROYO, M. G. Escola: terra de direito. In: ROCHA, M.I.A.; HAGE, S.M.(Orgs.). Escola de direito: reinventando a escola multisseriada. Belo Horizonte: Autêntica, 2010. p.09 - 14. (Coleção Caminhos da Educação do Campo, 2).

BAUMAN, Z. Desafios educacionais da modernidade líquida. Revista Tempo Brasileiro, Rio de Janeiro, n. 148, p.44 - 58, Jan./Mar. 2002.

CALDART, R.S. Educação do Campo. In: SANTOS, C.A. dos(Org.). Por uma Educação do Campo: Campo-Políticas Públicas-Educação. Brasília: INCRA/MDA, 2008. p. 67-86.

CALDART, R.S. Por uma educação do campo: traços de uma identidade em construção. In: ARROYO, M.G.; CALDART, R.S.; MOLINA, M.C.(Orgs.). Por uma educação do campo. 4 ed. Petrópolis: Vozes, 2009. p.149-150.

DUARTE, N. A pesquisa e a formação de intelectuais críticos na pós-graduação em educação. Perspectiva, Florianópolis, v. 24, n.1, p. 89-110, Jan./Jun. 2006. Disponível em: <http://www.perspectiva.ufsc.br $\geq$. Acesso em: 04 out. 2012.

FERNANDES, B.M. Diretrizes de uma caminhada. In: ARROYO, M. G; CALDART, R. S.; MOLINA, M. C. Por uma educação do campo. Petrópolis: Vozes, 2004. p. 133-145.

FREIRE, P.Pedagogia do oprimido. 17ed. Rio de Janeiro: Paz e Terra,1987.

FREIRE, P. Pedagogia da autonomia: saberes necessários à prática educativa. São Paulo: Paz e Terra, 1996.

FREIRE, P. Pedagogia da indignação: cartas pedagógicas e outros escritos. São Paulo: UNESP, 2000.

FREIRE, P. Educação como prática da liberdade. 25 ed. Rio de Janeiro: Paz e Terra, 2001. FREIRE, P. Educação e atualidade brasileira. 2 ed. São Paulo: Cortez, 2002.

DAMASCENO, M.N. Pedagogia do Engajamento. Fortaleza: EUFC, 1990. 
GADOTTI, M. Convite à leitura de Paulo Freire. São Paulo: Scipione, 1989.

GADOTTI, M.Lições de Freire. Revista da Faculdade de Educação, São Paulo, v. 23, n. 12, p.13 - 24, Jan./Dez.1997.

GIROUX, H. Os professores como intelectuais: rumo a uma pedagogia crítica da aprendizagem. Porto Alegre: Artmed, 1997.

NÓVOA, A. (Org.). Profissão: professor. Porto Editora, 1991. p.13 - 34.

SOUZA, M.A. de. Educação e movimentos sociais do campo: a produção do conhecimento no período de 1987 a 2007. Curitiba: Ed. UFPR, 2010.

Recebido em: 30/10/2012

Revisado em: 16/10/2013

Aprovado para publicação em: 01/04/2015

Publicado em: 31/08/2015 